\title{
STRATEGIES AND INNOVATIVE APPROACHES DEVELOPED FOR THE ACTIVE TARGETING OF DRUGS
}

\author{
SILVIA ARPICCO (*), ALESSANDRO MARENGO, BARBARA STELLA
}

SUNTO. - La capacità di trasportare in modo selettivo un farmaco, indipendentemente dal metodo di somministrazione, viene definita drug targeting. Tale concetto fu inizialmente suggerito da Paul Ehrilch con la teoria del magic bullet cioè un'ipotetica "pallottola magica" in grado di agire selettivamente sul bersaglio farmacologico. In ambito tecnologico farmaceutico il concetto di Ehrlich ha portato alla definizione di sistemi in grado di trasportare e rilasciare in modo selettivo i farmaci nel sito d'azione attraverso il coordinamento di tre componenti: i) un carrier polimerico idrosolubile ed inerte; ii) uno spaziatore biodegradabile interposto fra il polimero e il farmaco, in grado di dare un legame sensibile solo nel sito d'azione, rilasciando il principio attivo; iii) un farmaco, covalentemente legato allo spaziatore. Inoltre, può essere presente un agente "vettore", che ne promuova il direzionamento verso cellule bersaglio, riducendo le interazioni non specifiche. Il targeting attivo è reso possibile tramite la funzionalizzazione con porzioni che conferiscono la capacità di: i) riconoscere e legarsi specificatamente a ligandi o recettori di superficie di determinati tessuti (es. anticorpi monoclonali o frammenti, folato, transferrina); ii) rispondere a stimoli locali caratteristici dell'area patologica; iii) penetrare all'interno delle cellule e permettere al farmaco di raggiungere il proprio target intracellulare. Il direzionamento attivo, ottenuto legando sulla superficie molecole che siano direzionate verso siti specifici, aumenta attivamente la captazione dei nanosistemi. La creazione di sistemi basati sul targeting attivo permette loro di essere riconosciuti solo dalle cellule bersaglio. Il direzionamento è dovuto all'interazione del ligando specifico con antigeni e recettori overespressi nelle cellule di un particolare tessuto. Queste modifiche sulla superficie dei nanocarrier possono migliorare l'uptake del farmaco e ridurne gli effetti collaterali indesiderati.

$* * *$

(*) Dipartimento di Scienza e Tecnologia del Farmaco, Università degli Studi di Torino, Italia.E-mail: silvia.arpicco@unito.it 
ABSTRACT. - The ability to selectively deliver a drug to specific organs or tissues is called "drug targeting". This approach was initially reported by Paul Erlich describing a magic bullet able to act selectively towards a specific pharmacological target. In the pharmaceutical technology field the concept described by Ehrlich defines products able to selectively deliver and release the drug in a specific site thanks to the action of three components: i) an inert and water soluble polymeric carrier; ii) a biodegradable spacer linking polymer and drug; iii) a drug covalently linked to the spacer. Moreover, it is possible to add to the system a targeting agent that improves the targeting ability towards target cells reducing the nonspecific interaction of the system with normal ones. The active targeting is obtained through functionalization with portions that confer the ability to: i) recognize and specifically bind receptors overexpressed on the target cells or tissues (i.e. monoclonal antibodies or fragments, folate, transferrin); ii) be able to respond to local stimuli present in the pathological area; iii) allow the penetration of the drug into the target cells. The active targeting approach leads to an increased binding of the nanosystems to the specific site. The targeting ability is obtained thanks to the interaction of the targeting agents with specific antigens or receptors overexpressed on the target cells or tissues. The active targeted nanocarriers are characterized by increased drug uptake and reduced side effects.

\section{INTRODUCTION}

The side effects of drugs used in the therapy of some diseases, like cancer, would be reduced by delivering them selectively into those cells or tissues where their action is required.

Ideally, a drug designed for clinical use should have a high therapeutic index, which is the ratio of the drug's efficacy (therapeutic effect) to its toxicity (side effects). A drug with low therapeutic index but high activity should be delivered in a higher concentration to the target cells (thereby increasing efficacy) and away from non-target cells (thereby reducing toxicity). This delivery approach, called drug targeting, provides a means of increasing the therapeutic index of the drugs and achieving more effective therapy, with possible economic benefit.

Many different systems have been explored to target antineoplastic agents selectively to cancer cells or tissues. One of the more general approaches is to link a carrier molecule, such as a, protein, polysaccharide, natural or synthetic macromolecule, lectin or an antibody, by a covalent bond to an active moiety, such as an antitumoral drug or a cytotoxic protein (Fig. 1) (Byrn and Stowell, 1995; Maeda et at., 1992; Poznansky Juliano, 1984).

In searching for the ideal carrier, it is tempting to look for systems which can intrinsically recognise the target. Monoclonal antibodies 
have been shown to increase cytotoxicity and specificity in targeting antitumour drugs or toxins towards malignant cells (Reichert, 2012; Reichert and Dhimolea, 2012).

Glycoproteins are another category of macromolecules, that, depending on their charge and carbohydrate structure, are specifically recognised by certain tissues and cell groups within these tissues. In particular, asialoglycoproteins have been used for drug targeting to the liver for diagnostic and therapeutic purposes (Wadhwa and Rice, 1995). Moreover, hormones, lectins and transferrin can be used as carrier molecules with receptor-mediated uptake (Sasaki et al., 1993, Singh and Curtiss, 1994).

Many biologically active molecules have been delivered in the form of covalent conjugates with water-soluble, biodegradable polymers or natural macromolecules. The modification of drugs by conjugation with polymers has been investigated for a variety of purposes.

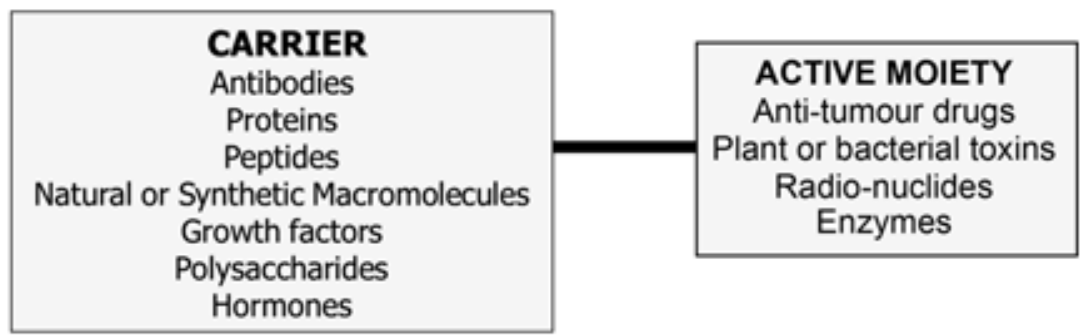

Fig. 1. Schematic representation of antitumoral conjugates.

A useful alternative approach to targeting antineoplastic drugs to tumour cells has been to use vesicular or particulate systems, such as liposomes, nanoparticles, microparticles for regional therapy or cells (erythrocytes, leukocytes, hepatocytes, platelets), to improve the drug concentration at the target by altering both tissue distribution and the drug's pharmacokinetic constant. Among vesicular particulates, liposomes have also been successfully used in clinical medicine for their ability to delivery drugs to the target cell or tissue, decreasing toxic side effects and also drug dosage (Wicki et al., 2015) (Fig. 2). With the so called classic liposomes, recognition of the specific cell or tissue depends mostly on a passive targeting mechanism, which is given by the bulk structural character of the carrier, such as its hydrophilicity or hydrophobicity, charge density, membrane fluidity or vesicles size. The most important drawback of this 
type of liposome is the very rapid elimination from the blood by the cells of the mononuclear phagocytic system (MPS). This prevents most of the administered liposomes from reaching their target site. The recent development of long-circulation liposomes (Stealth) obtained by coating the lipid bilayer with polyethylene glycol, has renewed interest in liposome delivery systems. These liposomes leak from the tumour vasculature to reach the tumour cells, exploiting the enhanced vascular permeability, limited recovery via post capillary venules and lack of lymphatic system.

To further enhance the cytotoxic effect, selective delivery of drugs to target cells can be achieved by conjugating lipid vesicles to various target ligands, such as antibodies, lectins, peptide hormones or growth factors (Sato and Sunamoto, 1992). In this way, the conjugated liposomes are potentially able to bind a specific receptor on target cell membranes, triggering their own internalisation by the mechanism of endocytosis. This is followed by the enzymatic digestion of the liposomes in the intracellular compartment (endosome, phagosome or acidosome), accompanied by the intracellular distribution of liposomal components to the cytosol.

The conjugates discussed above are characterised by the presence of one or more covalent bond. The nature of the bond as well as its chemical and/or biological stability should be considered in detail since, in order to maximise its therapeutic index, the drug must be released from the conjugate only at the target site. The bond designed to link the active moiety to the carrier must therefore be sufficiently stable in the blood, but able to be cleaved when the conjugate reaches the target (tissue or cells).

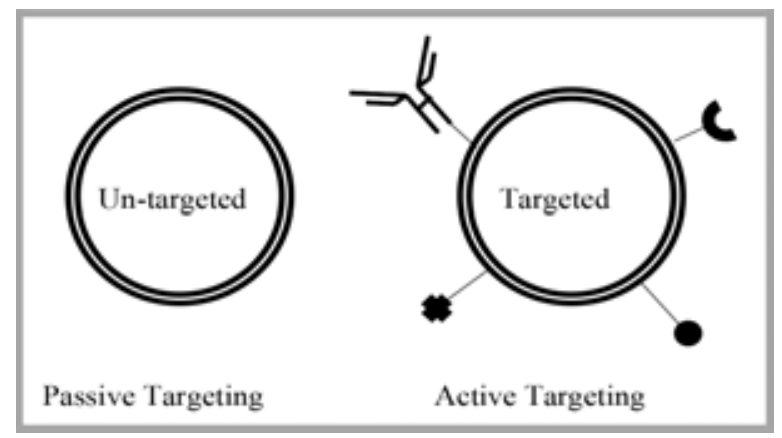

Fig. 2. Liposomes classic (passive targeting) and decorated with targeting agents (active targeting). 
Several classes of crosslinking reagents have been synthesised, with the aim of improving the characteristics of the conjugates (Mattson G. et al., 1993). Crosslinking reagents can be classified on the basis of the following characteristics: chemical specificity, length of bridge formed, crosslinking groups: [identical (homobifunctional) or different (heterobifunctional)], activity of groups (chemical or photochemical), presence of a cleavable bond, and physical chemistry properties (solubility, hydrophilicity or hydrophobicity).

Many factors must be evaluated in selecting an appropriate crosslinking reagent for the preparation of drug-carrying conjugate. Initially, it must be decided whether the best method of linkage can be achieved by using existing groups present in the carrier or in the active biological agent, or by introducing special reactive groups into agents. A group must be used that can be cleaved intracellularly to regenerate the original active agent or a derivative of it that allows cytotoxic action. Reactive groups that can be coupled using a crosslinker include primary amines, sulphydryls, carbonyls and carboxylic acids. Additionally, any reactive group can be coupled with a non-selective linker, such as a photoreactive phenyl azide.

Conjugate preparation requires a separate derivatization of drug and carrier with the linking agents. Then, after purification, the newlyinserted groups can react with each other in order to produce a stable and homogeneous conjugate population. The linkage method must be selected so as to avoid both the formation of homopolymers of antibody or agent, and the aggregation of the conjugate.

In preparing carrier-drug conjugates, it is important to take into account the stability of the bond. Usually a stable linkage is selected, but an enzymatically-degradable bond must be introduced in order to allow efficient release of the active molecule. In some cases, the best selection is an aminoacidic bridge or disulfide groups.

The choice of an acid $\mathrm{pH}$ sensitive linkage is very important if the drug must be delivered to a specific intracellular target (endosomes or lysosomes) whose intravesicular $\mathrm{pH}$ lies between $\mathrm{pH} 5.5$ and 6.5 (Braslawsky et al., 1991). Another important characteristic of linking agents is the length of the spacer arms or bridges. The most apparent attribute of the bridge is its ability to deal with steric hindrances of the moieties to be linked. Because steric effects dictate the distance between potential reaction sites for crosslinking, different lengths of bridge are required. In the case of the macromolecular/particulate con- 
jugate, the length of the link may be of strategic importance, since steric hindrance can reduce the accessibility to serum proteins and proteases, which are considered very important factors for in vivo stability and pharmacological activity.

The covalent attachment of biologically-active compounds to a carrier is not therefore simply a way to attach two moieties together, but it is a method to alter the biodistribution, pharmacokinetics, and often the toxicity of the parent compounds. In other words, a rationally designed linkage procedure can modify the pharmacokinetic and pharmacodynamic parameters of a drug.

\section{IMMUNOTOXINS}

Immunotoxins are protein-based therapeutics consisting of a targeting moiety linked or fused to a killing moiety. The target moiety can be an antibody or a ligand directed against a receptor or cell-surface antigen that is specific for the targeted disease, while the active moiety is a member of a class of highly toxic proteins or enzymes. Essentially, any molecule that will induce cell death by directly interfering with the cell machinery, by modifying the cell membrane, or by inducing apoptotic proteins can be used. Because of the enzymatic potency of these proteins, a small number of toxin molecules successfully delivered to the cytoplasm (or to the ribosomal compartment) may be lethal to the cell (Pirie et al., 2011).

Initially, immunotoxins comprised monoclonal antibodies or growth factors chemically conjugated to cytotoxic plant or bacterial toxins, but these have largely been replaced by recombinant methods, thanks to their considerable design flexibility and product homogeneity.

Monoclonal antibody technology is now mature, fully humanized antibodies are in therapeutic use, and fragments of different complexity are available. Thus the most energetic and continuous efforts are directed to manipulating the killing moiety, where the success of delivering the cytotoxic domain of an immunotoxin to the cell cytoplasm depends on a series of steps, each having varying degrees of efficiency depending on the cell type, antigen density, binding affinity, internalization/recycling, and subcellular trafficking or endosomal escape. High anticancer activity is unfortunately usually contrasted by critical drawbacks, which are caused by varying degrees of nonspecific toxicity, mainly affecting hepatocytes, the kidneys and the vascular endothelium. 


\section{ANTIBODY DRUG-CONJUGATES}

Monoclonal antibodies have also been covalently linked to anticancer drugs, enabling high doses of the cytotoxic agent to be specifically delivered to cancer cells, largely sparing normal tissues (Alley et al., 2010). As for immunotoxins, the antibodies used are specific for antigens that are highly expressed on cancer cells; they are conjugated to drugs through different specialized chemical linkers. Potent cytotoxic agents may be needed to maximize the efficacy of drug conjugates. The drug must also be inactive and nontoxic in the conjugated form, to avoid systemic toxicity, and it should be released inside the cancer cell to exert its activity. A crucial point concerns the choice of linker-spacer that connects the drug molecules to the antibody. Several strategies have been developed to selectively release the therapeutic agent from a conjugate only after internalization, and by intracellular metabolism of tumor cells. The principal mechanisms involve the use of spacers that are cleavable by proteolysis of enzymes overexpressed in tumor tissues, or of acid-sensitive linkages cleavable under the acidic conditions present in tumors, endosomes, and lysosomes. Furthermore, exploiting the tumor's hypoxic environment can lead to enhanced activity of reductive enzymes, and therefore even higher glutathione concentrations. Reduction reactions can then be used to efficiently release active drug from the non-toxic prodrug. Self-immolative spacers have also been proposed, comprising drug, linker, and trigger. The tumor-specific cleavage reaction takes place between trigger and linker, to form a drug-linker derivative. This then degrades spontaneously by elimination or cyclization, to release the free drug, preferably inside the affected tissues. As a result, exposure of normal tissues is limited, at least in theory, leading to a more favorable toxicity profile. Furthermore, especially for antibody drug conjugates not prepared as fusion constructs, the method of conjugation, which determines the drug loading stoichiometry and homogeneity, has been shown to play a crucial role not only in pharmacokinetics, but also in activity, potency, and tolerability.

Unlike immunotoxins, several antibody drug conjugates are currently in advanced clinical trials for a variety of tumors (both hematologic and solid type) and great effort is being made by pharmaceutical companies to reach the goal of high specificity, high potency and lower toxicity (FitzGerald et al., 2011).

Among the drugs used for this purpose are different classes of 
molecules, the main ones being the calicheamicins, duocarmycins, auristatins and maytansinoids; other potent molecules from different natural sources are also under investigation.

The first approved antibody drug conjugate was gemtuzumab ozogamicin (Mylotarg ${ }^{\mathrm{TM}}$, Pfizer Inc.), an anti-CD33 calicheamicin conjugate active against hematologic malignancies (Fig. 3) (Ricart et al., 2011). Gemtuzumab ozogamicin consists of a humanized anti-CD33 antibody attached, via a bifunctional hydrazone linker, to the cytotoxic drug calicheamicin (Sievers et al., 2001).

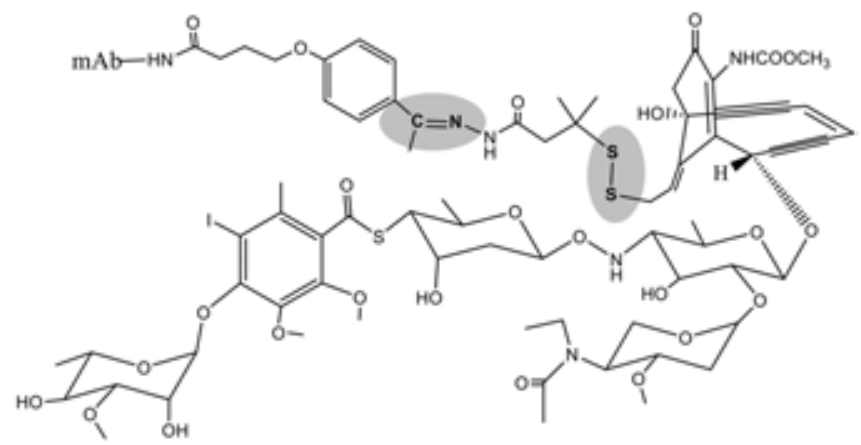

Fig. 3. Structure of N acetyl, gamma calicheamicin conjugate Mylotarg. In grey color are represented the two chemically labile linkers.

\section{LINKING AGENTS IN PARTICULATE VEHICLES: LIPOSOMES}

One of the more popular experimental approaches to controlled drug delivery has been the use of liposomes or phospholipid vesicles. A particulate tool might improve the therapeutic indices of highly toxic drugs: indeed, liposomes are able to entrap drugs and protect them from drug breakdown and can even act as a sustained release system, altering the biodistribution of the free drug (reducing aspecific toxicity). Liposomes, however, are rapidly taken up by phagocytic cells; in recent years, using an improved knowledge of liposome physiology and membrane biophysics, several approaches have been attempted to rationally design highly effective liposomes. Liposomes can now be obtained in a form that is sterically stabilised, polymorphic (cationic, fusogenic), or that has reduced in vivo uptake (Stealth) and provided with specific recognition (targeting). To obtain good results in targeting 
when using liposomes for drug delivery, the size of the liposomes, drug loading and liposome stability must be considered, as must the efficiency of the coupling reaction with the targeting device or masking agents.

To achieve more specific drug delivery, liposomes have been conjugated with monoclonal antibodies or other targeting agents (Nogueira et al., 2016).

\section{REFERENCES}

Alley SC, Okeley NM, Senter PD. Antibody-drug conjugates: targeted drug delivery for cancer. Curr Opin Chem Biol. 2010, 14:529-37.

Braslawsky GR, Kadow K, Knipe J, MCGoff K, Edson M, Kaneko T et al. Adriamycin(bydrazone)-antibody conjugates require internalization and intracellular acid bydrolysis for antitumor activity. Cancer Immunol Immunother. 1991, 33 : 367-374.

Byrn SR, Stowell JG. Drug targeting using conjugates: the importance of pharmaceutical chemistry. J Drug Targeting 1995, 3:239-241.

FitzGerald DJ, Wayne AS, Kreitman RJ, Pastan I. Treatment of hematologic malignancies with immunotoxins and antibody-drug conjugates. Canc Res. 2011, 71:6300-9.

Maeda H, Seymour LW, Miyamoto Y. Conjugates of anticancer agents and polymers: advantages of macromolecular therapeutics in vivo. Bioconj Chem. 1992, 3:351-62.

Mattson G, Conklin E, Desai S, Nielander G, Savage MD, Morgensen S. A practical approach to crosslinking. Mol Biology Rep. 1991, 317:167-83.

Nogueira E, Gomes AC, Preto A, Cavaco-Paulo A. Design of liposomal formulations for cell targeting. Colloids Surf B Biointerfaces. 2016, 14:529-37.

Poznansky MJ, Juliano RL. Biological approaches to the controlled delivery of drugs: a critical review. Pharmacol Rev. 1984, 36:277-34.

Pirie CM, Hackel BJ, Rosenblum MG, Wittrup KD. Convergent potency of internalized gelonin immunotoxins across varied cell lines, antigens, and targeting moieties J Biol Chem. 2011, 286:4165-72.

Reichert JM. Which are the antibodies to watch in 2012? mAbs. 2012, 4:1-3.

Reichert JM, Dhimolea E. The future of antibodies as cancer drugs. Drug Discovery Today. 2012, 17:954-63.

Ricart AD. Antibody-drug conjugates of calicheamicin derivative: gemtuzumab ozogamicin and inotuzumab ozogamicin. Clin Cancer Res. 2011, 17:6417-27.

Sasaki K, Kohgo Y, Kato J, Kondo H, Niitsu Y. Intracellular metabolism and cytotoxicity of transferrin-neocarzinostatin conjugates of differing molar ratios. Japanese J Cancer Res. 1993, 84:191-96.

Sato T, Sunamoto J. Recent aspects in the use of liposomes in biotechnology and medicine. Prog in Lipid Res. 1992, 31:345-372. 
Singh V, Curtiss R. Hormonotoxins. The role of positive charge of lysine residue on the immunological, biological and cytotoxic properties of ovine lutropin-S-S-gelonin conjugates. Mol Cell Biochem. 1994, 130:91-101.

Sievers EL, Linenberger M. Mylotarg: antibody-targeted chemotherapy comes of age. Curr Opin Oncol. 2001, 13:522-7.

Wadhwa MS, Rice KG. Receptor mediated glycotargeting. J Drug Targeting, 1995, 3:111-27.

Wicki A, Witzigmann D, Balasubramanian V, Huwyler J. Nanomedicine in cancer therapy: challenges, opportunities, and clinical applications. J Control Rel 2015, 200:138-57 